\title{
Olea europaea Linn (Oleaceae) Fruit Pulp Extract Suppresses Sterol Regulatory Element-Binding Proteins-1c via AMP-Activated Protein Kinase Activation in Human Hepatic Cells
}

\author{
Hyun Kang \\ Department of Medical Laboratory Science, College of Health Science, Dankook University, Cheonan-si, Chungnam, 330-714,
} Republic of Korea

*For correspondence: Email: hkang@dankook.ac.kr; Tel: 82-41-550-1452; Fax: 82-41-559-7934

Received: 10 May 2014

Revised accepted: 4 July 2014

\begin{abstract}
Purpose: To investigate the molecular mechanisms underlying the role of Olea europaea Linn (Oleaceae) fruit pulp extract (OPF) in the prevention of high glucose-induced lipid accumulation in human HepG2 hepatocytes.

Methods: HepG2 cells were pretreated with various concentration of $\operatorname{OPF}(0,10,20,40$ and $80 \mu \mathrm{g} / \mathrm{ml})$ and then treated with serum-free medium with normal glucose $(5 \mathrm{mM})$ for $1 \mathrm{~h}$, followed by exposure to high glucose (25 mM D-glucose) for $24 \mathrm{~h}$. Cell viability and cytotoxicity parameters were measured using $\mathrm{LDH}$ and MTT assay while triglyceride and total cholesterol levels were evaluated using respective enzymatic reagent kits. Protein expressional levels were analyzed by Western blotting.

Results: OPF did not influence the cell viability (up to $200 \mu \mathrm{g} / \mathrm{ml}$ ) and showed any signs of cytotoxicity (up to $80 \mu \mathrm{g} / \mathrm{ml}$ ). OPF significantly attenuated lipid accumulation in human HepG2 hepatocytes when exposed to high glucose (25 mM D-glucose) in a dose-dependently ( $p<0.05,0.01$ and 0.001 at 20, 40 and $80 \mu \mathrm{g} / \mathrm{ml}$ concentrations, respectively). Nile red staining showed that $10,20,40$ and $80 \mu \mathrm{g} / \mathrm{ml}$ concentrations of OPF reduced lipid accumulation by $25,33.7(p<0.05), 43.7(p<0.01)$ and $52.5 \%(p$ $<0.001)$, respectively. The increased levels of triglycerides and total cholesterol contents were also attenuated by OPF ( $p<0.001$ at $80 \mu \mathrm{g} / \mathrm{ml})$. Further, OPF attenuated the expression of fatty acid synthase and sterol regulatory element-binding protein-1. Adenosine monophosphate-activated protein kinase was also activated by OPF treatment when exposed to high glucose (25 mM D-glucose) in human HepG2 hepatocytes.

Conclusion: This study indicates that OPF has hypolipidemic effects by inhibiting lipid biosynthesis mediated via AMPK signaling. Thus, this extract can be potentially developed into an anti-obesity agent.
\end{abstract}

Keywords: Olea europaea, Fruit pulp extract, Lipogenesis, AMPK SREBP-1, Anti-obesity; HepG2 cells

Tropical Journal of Pharmaceutical Research is indexed by Science Citation Index (SciSearch), Scopus, International Pharmaceutical Abstract, Chemical Abstracts, Embase, Index Copernicus, EBSCO, African Index Medicus, JournalSeek, Journal Citation Reports/Science Edition, Directory of Open Access Journals (DOAJ), African Journal Online, Bioline International, Open-J-Gate and Pharmacy Abstracts

\section{INTRODUCTION}

Abnormal lipid and lipoprotein metabolism are known to result in dyslipidemia such as elevation of plasma cholesterol and/or TGs and decreased levels of high-density lipoprotein (HDL). Fatty liver disease is related to fat accumulation, high triacylglycerol, low high-density lipoprotein cholesterol (HDL-C), high low-density lipoprotein cholesterol (LDL-C), and insulin resistance [1]. 
A number of proteins associated with dyslipidemia have been reported to play important roles in lipogenesis, including fatty acid synthase (FAS), sterol regulatory element binding proteins (SREBPs) [2]. FAS are a multiple enzyme complex that catalyzes the synthesis of palmitate from acetyl-C glucose and malonyl-C glucose. Expression of FAS is regulated by multiple transcription factors. SREBPs, a transcription factor family, regulate the expression of enzymes for the synthesis of fatty acid, cholesterol, triacylglycerol, and phospholipids, suggesting that the protein family plays a central role in energy homeostasis via modulation of glycolysis, lipogenesis, and adipogenesis .

Adenosine monophosphate-activated protein kinase (AMPK) is a serine threonine kinase comprising a heterotrimeric complex and regarded as an energy sensor in most tissues. AMPK regulates cellular lipid metabolism by increasing fatty acid oxidation and constitutive lipoprotein exocytosis [3]. In the liver, activated AMPK phosphorylates and inactivates the ratelimiting enzymes of lipogenesis such as ACC, suggesting that AMPK/ACC signaling plays a critical role in hepatic lipid homeostasis [4].

In search of a potential anti-obesity agent from natural products we evaluated Olea europaea Linn. (family, Oleaceae), commonly known as olive is among the oldest known cultivated trees in the world with immense medicinal values. Olives and its associated products have been used widely as folk medicines [5]. Experimental studies on the fruits and leaf extracts from olives show that they possess anti-thrombotic, antihypertensive, anti-cancer, hypoglycemic, antiinflammatory, anti-microbial and antiatherogenic properties [6,7]. The major active components of olives are phenolic constituents $[8,9]$. This study aimed to examine whether Olea europaea Linn (Oleaceae) Fruit Pulp extract (OPF) could suppress the hepatic lipid induced by high glucose and regulate the lipid metabolism.

\section{EXPERIMENTAL}

\section{Materials and reagents}

Green olive fruits collected at the end of September to about the middle of November were obtained from the local market, Seoul, South Korea. The fruits were authenticated by Professor Jong-Bo Kim, a taxonomist, Konkuk University, Korea, and a voucher specimen (OL-
KU2012) was kept in the university herbarium for future reference. All reagents used in this study were of the highest commercial grade available.

\section{Preparation of the Olea europaea fruit pulp extract}

We employed a previous preparation method for this extract $[8,9]$. Briefly, $500 \mathrm{~g}$ of the fruit were ground in a mixer and defatted three times with three volumes of $80 \%$ ethanol. The residue (fruit pulp) was extracted with absolute ethanol (EtOH) at $1: 10$ ratio $(w / v)$ for $2 \mathrm{~h}$ on a heated mantle at $70-80{ }^{\circ} \mathrm{C}$. The supernatant was filtered and concentrated in a rotatory evaporator at $50{ }^{\circ} \mathrm{C}$. The ethanol extract obtained $(180 \mathrm{~g})$ was resuspended in water:EtOH $(9: 1, \mathrm{v} / \mathrm{v})$ and partitioned successively with $n$-hexane, ethyl acetate (EA) and n-butanol to obtain final yields of $19.4,52$ and $27.27 \%$, respectively. EA fraction of olive pulp fruit extract was dissolved in sterile distilled water and filtered on $0.22 \mu \mathrm{m}$ filters before use.

\section{Cell culture and treatment}

Human HepG2 hepatocytes obtained from the American Type Culture Collection (Rockville, MD) were cultured in Dulbecco's modified Eagle's medium (DMEM) containing normal glucose (5.5 mM d-glucose), supplemented with $10 \%$ heat-inactivated foetal bovine serum (FBS; Invitrogen). Cells were cultured in a humidified 5 $\% \mathrm{CO}_{2}$ incubator at $37{ }^{\circ} \mathrm{C}$ in complete medium supplemented with $10 \%$ FBS to $80 \%$ confluence for use in the assays. OPF was dissolved in dimethyl sulfoxide (DMSO) added directly to serum-free culture medium. The final concentration of DMSO did not exceed $0.1 \%$ (v/v) and did not affect cell viability nor produced cytotoxicity. A cell model of the high glucoseinduced accumulation of hepatic lipids was prepared by exposing HepG2 cells to $25 \mathrm{mM}$ of glucose for $24 \mathrm{~h}$.

\section{Measurement of cell viability and cytotoxicity}

Cells were cultured at $37{ }^{\circ} \mathrm{C}$ in medium containing $10 \% \mathrm{FBS}$ at a density of $4 \times 10^{4}$ cells $/ 500 \mu \mathrm{L}$ in 48-well plates. After $24 \mathrm{~h}$, the growth medium was replaced with serum-free medium and the cells were treated with different concentrations of OPF $(10-100 \mu \mathrm{g} / \mathrm{ml})$ or an equal volume of DMSO for $24 \mathrm{~h}$ at $37^{\circ} \mathrm{C}$. The culture medium was used in a lactate dehydrogenase (LDH) assay, with the absorbance at $490 \mathrm{~nm}$ measured using a microplate reader (Varioskan; Thermo Electron, Waltham, MA). The percent cytotoxicity was calculated based on the absorbance relative to 
the controls. Cells were treated with MTT solution (final concentration, $0.5 \mathrm{mg} / \mathrm{ml}$ ) for $1 \mathrm{~h}$. The dark blue formazan crystals that formed in intact cells were solubilized with DMSO, and the absorbance at $570 \mathrm{~nm}$ was measured with a microplate reader. Cell viability was calculated based on the absorbance of the OPF-treated cells relative to that of control vehicle-treated cells.

\section{Nile red stain test}

Human HepG2 hepatocytes were seeded in a 6well plate $\left(3 \times 10^{6}\right.$ cells/well $)$ and treated with glucose $(25 \mathrm{mM})$ with indicated concentrations of HCE for $24 \mathrm{~h}$. The cells were washed twice with PBS and fixed with $4 \%$ formaldehyde in PBS for $1 \mathrm{~h}$ and then stained with $1 \mu \mathrm{g} / \mathrm{ml}$ Nile red for 30 min at room temperature. After staining, the distribution of lipid in cells was immediately analyzed by a FACScan flow cytometer (Becton Dickinson, Mountain View, CA, USA). Lipidbound Nile red fluorescence was detected using inverted fluorescence microscopy.

\section{Determination of triglyceride and total cholesterol levels}

The intracellular triglyceride and total cholesterol contents were measured in cell lysates and expressed as micrograms of lipid per milligram of cellular protein. HepG2 cells were seeded in 100$\mathrm{mm}$ culture dishes. Twenty-four hours after treatment, the cells were homogenized in $1 \mathrm{~mL}$ of PBS. The homogenates were extracted with $3 \mathrm{ml}$ of chloroform and methanol $(2: 1, v / v)$. The mixture was vortexed vigorously, allowed to separate into two phases, and centrifuged (3000 $\mathrm{rpm}, 10 \mathrm{~min}, 4{ }^{\circ} \mathrm{C}$. An aliquot of the organic phase was evaporated under nitrogen gas until dry. The resulting pellet was dissolved in PBS containing $1 \%$ Triton $\mathrm{X}-100$, and the protein concentration was measured. The intracellular triglyceride and total cholesterol contents were determined using an enzymatic reagent kit (Asan Pharm. Co., Seoul, Korea) at $550 \mathrm{~nm}$ and 500 $\mathrm{nm}$, respectively, and normalized to the protein concentration.

\section{Western blot analysis}

Human HepG2 hepatocytes were seeded in a 10 $\mathrm{cm}$ dish $\left(1 \times 10^{6}\right.$ cells/well $)$ and treated with glucose $(25 \mathrm{mM})$ at indicated concentrations of OPF for $24 \mathrm{~h}$. The proteins of the cells were harvested in a cold radio immunoprecipitation assay (RIPA) buffer (1 \% NP-40, 50 mM Trisbase, $0.1 \%$ SDS, $0.5 \%$ deoxycholic acid, 150 $\mathrm{mM} \mathrm{NaCl}, \mathrm{pH}$ 7.5). Equal amounts of protein samples were subjected to SDS-polyacrylamide gel electrophoresis and electro-transferred to nitrocellulose membranes (Millipore, Bedford, MA, USA). The membranes were blocked with 5 $\%$ nonfat milk powder with $0.1 \%$ Tween-20 in TBS and then incubated with the first antibody at $4{ }^{\circ} \mathrm{C}$ overnight. Thereafter, membranes were washed three times with $0.1 \%$ Tween-20 in PBS and incubated with the secondary antibody to anti-mouse horseradish peroxidase (GE Healthcare, Little Chalfont, Buckinghamshire, UK). Antibodies against AMPK and phosphoAMPK were purchased from Cell Signaling Technology (Beverly, MA, USA). FAS and SREBP-1C antibodies were obtained from Santa Cruz Biotechnology (Santa Cruz, CA, USA). Band detection was revealed by enhanced chemiluminescence using ECL Western blotting detection reagents and exposed ECL hyper film in FUJIFILM LAS-3000 (Tokyo, Japan).

\section{Statistical analysis}

All data are presented as mean \pm SD $(n=3)$. Statistical analyses were performed with SAS statistical software (SAS Institute, Cray, NC, USA) using one-way analysis of variance, followed by Dunnett's multiple range tests. $P<$ 0.05 was considered statistically significant.

\section{RESULTS}

\section{Effect of OPF on HepG2 cell viability}

We first determined the concentration dependence of the cytotoxic effects of OPF by directly adding OPF to the culture medium at various concentrations $(10-200 \mu \mathrm{g} / \mathrm{ml})$ for 24 $\mathrm{h}$, and the cell viability was measured using MTT assays (Fig 1).

OPF also showed no signs of cytotoxicity at indicated concentrations (10-100 $\mu \mathrm{g} / \mathrm{ml})$ under normal glucose and high glucose conditions in HepG2 cells (Fig 2A and B). Considering the results we used OPF in the range of $10-80 \mu \mathrm{g}$ $/ \mathrm{ml}$, respectively for further experiments.

\section{OPF attenuates lipid accumulation in human HepG2 hepatocytes}

To assess the hypolipidemic effects of OPF in vitro, HepG2 cells were pretreated with various concentration of OPF $(10,20,40$ and $80 \mu \mathrm{g} / \mathrm{ml})$ and treated with serum-free medium with normal glucose $(5 \mathrm{mM})$ for $1 \mathrm{~h}$, followed by exposure to high glucose (25 mM D-glucose) for $24 \mathrm{~h}$. Nile red staining showed that $10,20,40$, and 80 $\mu \mathrm{g} / \mathrm{ml}$ concentrations of OPF reduced lipid accumulation by $25,33.7,43.7$ and $52.5 \%$, respectively (Fig $3 A$ ). 


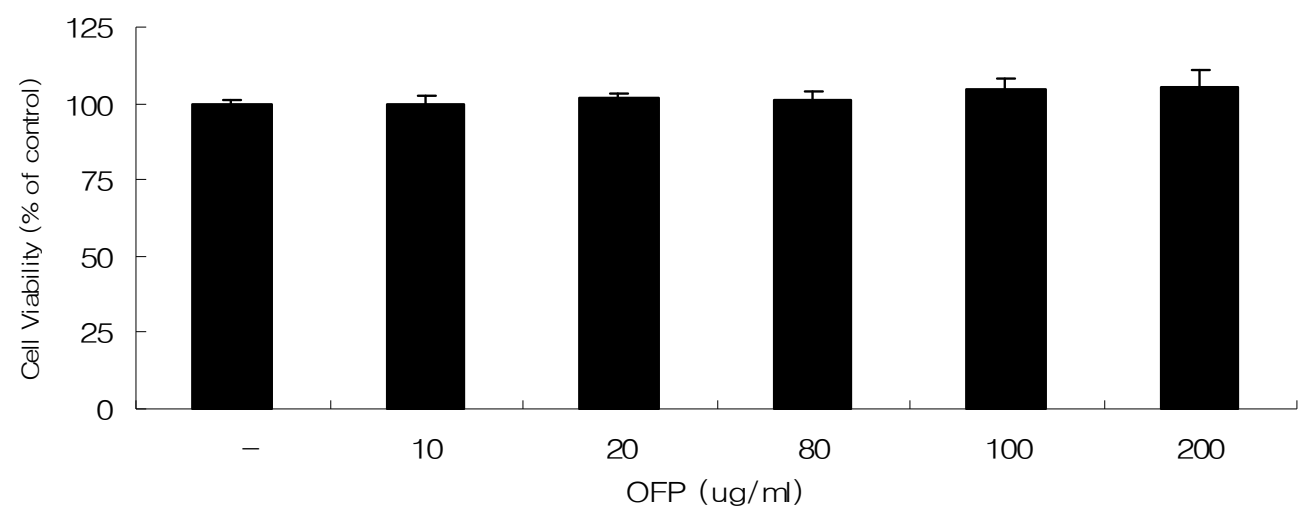

Figure 1: Effect of OPF on overall cell viability in human HepG2 hepatocytes. Cell viability was assessed by MTT assay and expressed as percentage of the vehicle controls. Data expressed are means \pm SD of three independent experiments conducted in triplicate. No significant difference exists when compared to control group. OPF = Olea europaea extract

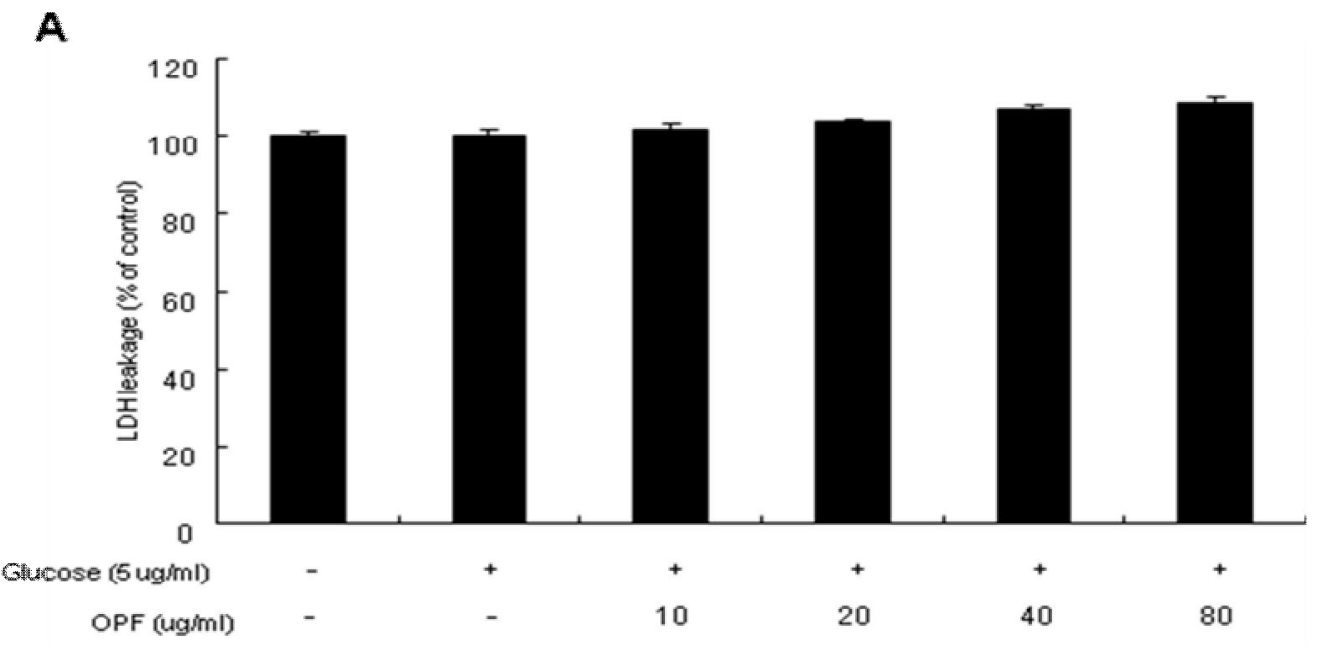

\section{B}

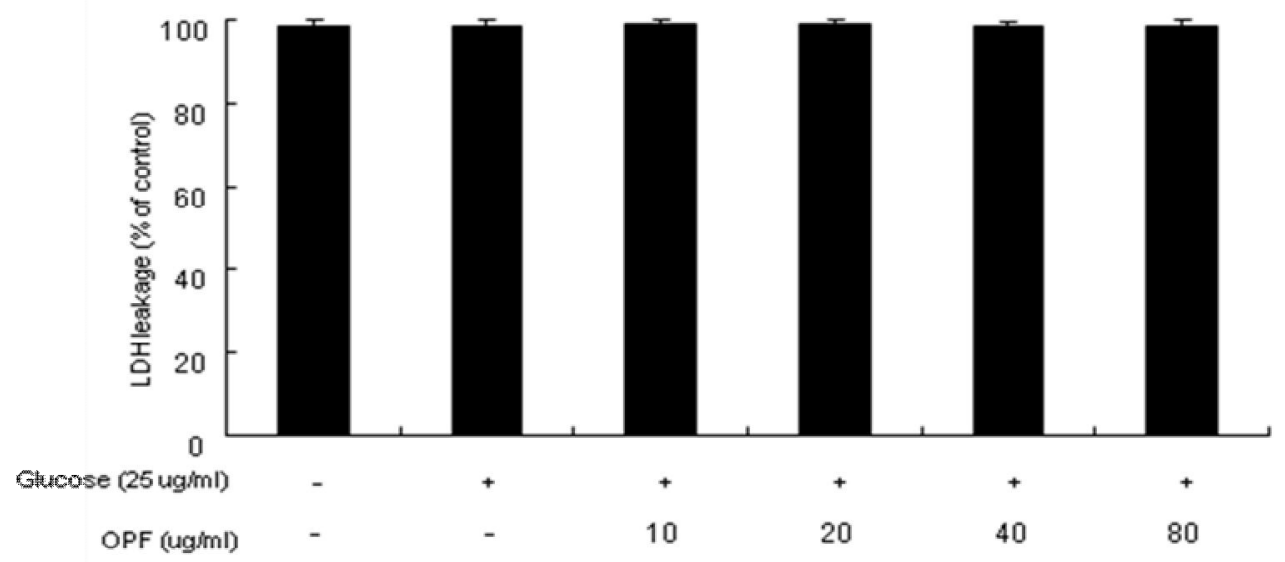

Figure 2: Effect of OPF on HepG2 cell cytotoxicity. Cytotoxic effects of OPF on human HepG2 hepatocytes under normal $(A)$ and high glucose $(B)$ conditions, respectively. Cell cytotoxicity were assessed by LDH assay and expressed as percentages of the vehicle controls. Data expressed are means \pm SD of three independent experiments conducted in triplicate. No significant difference was found compared to control group; OPF = Olea europaea extract 
A
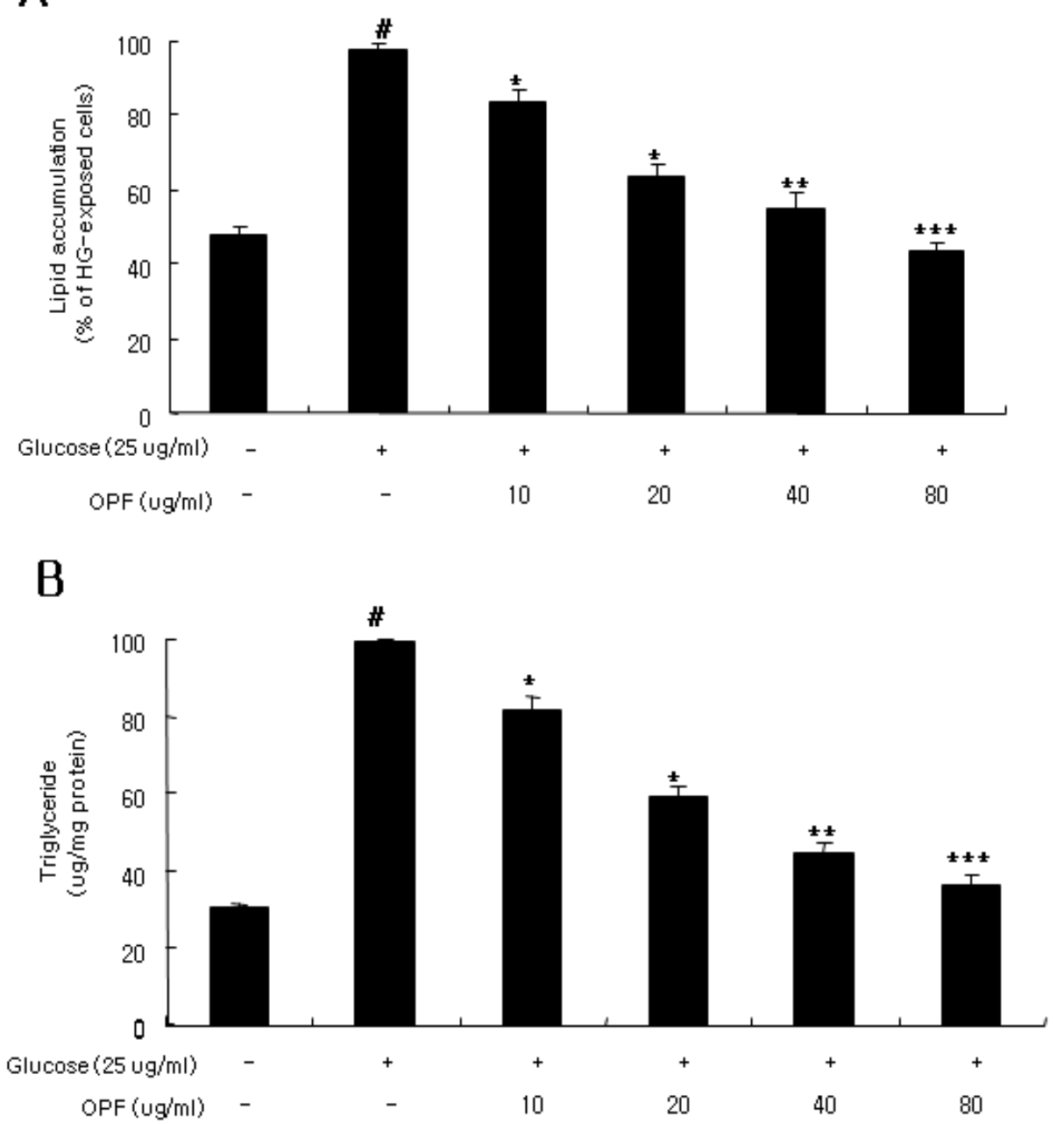

C

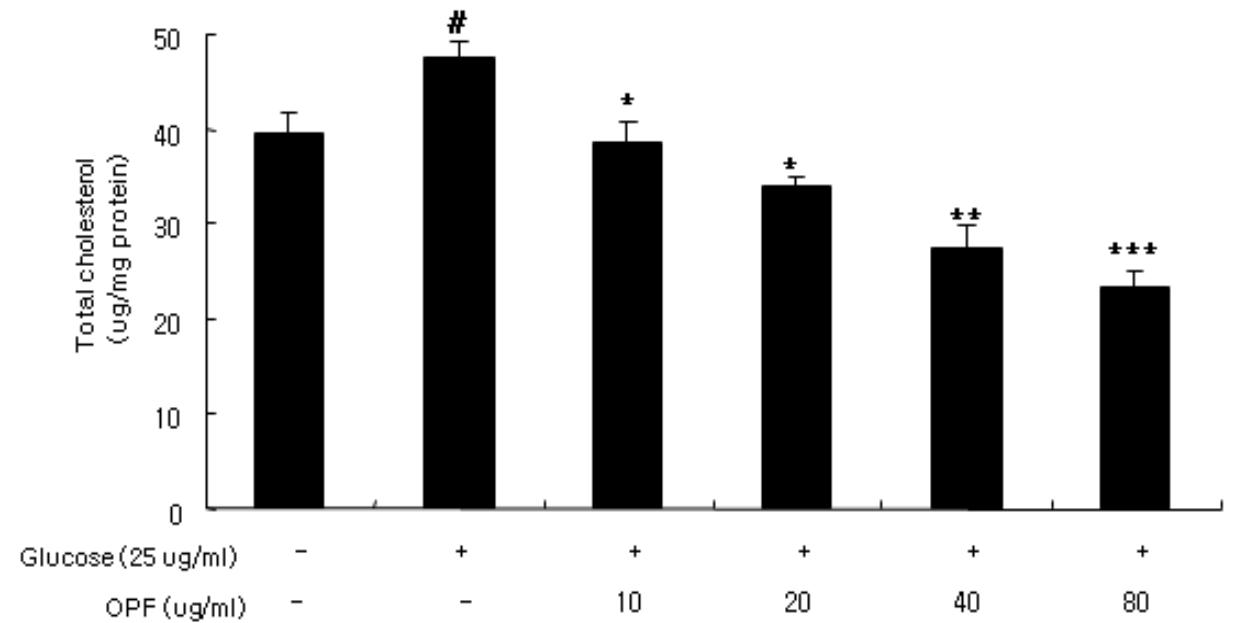

Figure 3: OPF attenuates high glucose-induced lipid accumulation in human HepG2 hepatocytes. A: Effect of OPF on high glucose-induced lipid accumulation in human HepG2 hepatocytes. B: Intracellular triglyceride and C: total cholesterol contents in cell lysates. Data shown are the means \pm SD of three independent experiments performed in triplicate; ${ }^{\#} p<0.001$ vs. the control; ${ }^{*} p<0.05,{ }^{* *} p<0.01$ and ${ }^{* * *} p<0.001$ vs. high glucose-exposed cells, respectively; OPF = Olea europaea extract 
The effects of OPF on the triglyceride and total cholesterol levels showed that 20, 40, and 80 $\mu \mathrm{g} / \mathrm{ml}$ of OPF reduced the triglyceride levels significantly, in the high glucose-treated cells by 46.2, 57.5 and $61.5 \%$, respectively (Fig 3B). OPF at indicated concentrations also decreased the cholesterol content of HepG2 cells incubated in high glucose for $24 \mathrm{~h}$ by $41.3,57.2$ and 63.5 $\%$, at 20,40 , and $80 \mu \mathrm{g} / \mathrm{ml}$ concentrations, respectively (Fig $3 \mathrm{C}$ ). These results indicate that OPF can attenuate high glucose-mediated lipid accumulation in human HepG2 hepatocytes.

OPF inhibits lipid accumulation by down regulation of FAS expression in human HepG2 hepatocytes through SREBP-1c inactivation

We examined the status of SREBP-1c in high glucose-induced HepG2 cells in the presence or absence of OPF at indicated concentrations. SREBP-1 protein levels were increased markedly in cells treated with high glucose $(25 \mathrm{mM})$ for 12 h (Fig 4, upper panel).

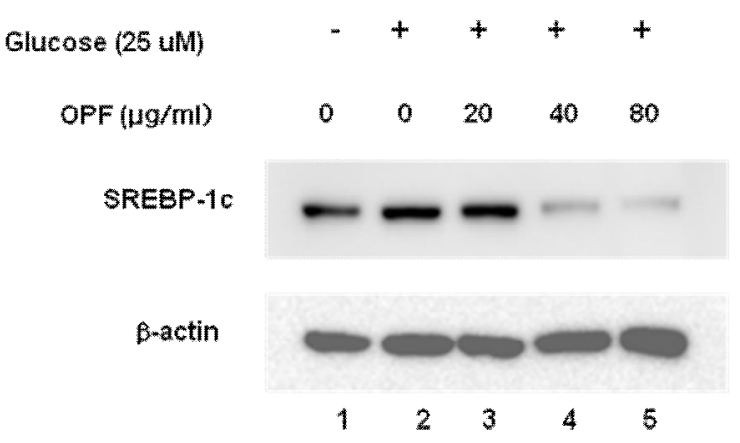

Figure 4: Effect of OPF treatment on SREBP-1c protein expression in human HepG2 hepatocytes. SREBP-1c protein levels in the cell lysates were detected by Western blot analysis. All experiments were performed in triplicate. OPF: Olea europaea Linn (Oleaceae) Fruit Pulp extract

\section{OPF promotes AMPK phosphorylation in human HepG2 hepatocytes}

The phosphorylation of AMPK was determined in HepG2 cells under high glucose conditions by Western blotting. HepG2 cells cultured in serumfree medium with normal glucose $(5 \mathrm{mM})$ were pretreated with OPF $(20,40$ and $80 \mu \mathrm{g} / \mathrm{ml})$ for 1 $\mathrm{h}$, followed by exposure to high glucose $(25 \mathrm{mM})$ for an additional $2 \mathrm{~h}$. Although the phosphorylation of AMPK was significantly suppressed in cells treated with high glucose (25 $\mathrm{mM})$, OPF dose-dependently restored the phosphorylation of AMPK in OPF-pretreated cells (Fig 5).

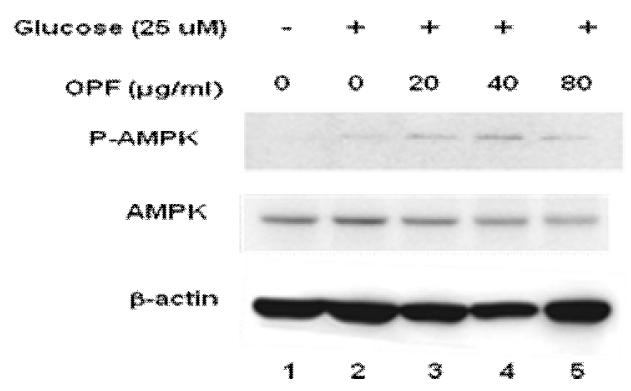

Figure 5: Effect of OPF treatment on PAMPK/AMPK protein expression in human HepG2 hepatocytes ( $\mathrm{n}=$ 3 ). The protein levels of PAMPK/AMPK in the cell lysates were detected by Western blot analysis. $\beta$ actin was used as an internal control; OPF = Olea europaea extract

\section{DISCUSSION}

The hepatic hypolipidemic mechanism of OPF showed high relevant expression of lipogenic enzyme, cholesterol biosynthesis and TG biosynthesis in HepG2 cells. Taken together, these observations suggest that the hypolipidemic effects of OPF may require the AMPK signaling pathway. Activation of AMPK leads to regulation of a number of downstream targets involved in lipid metabolism [10]. The regulation of AMPK activation and the most effective constituent in OPF need to be elaborated.

Several natural products from plant origin have been suggested to be capable of preventing obesity via regulating hyperlipidemia and reducing adipose tissue mass, thus suppressing the occurrence of the metabolic, hepatic, and cardiovascular alterations associated with obesity [11-13]. Many studies have indicated that antioxidant phenolic compounds have been used in cellular and animal models for the treatment of obesity and hypolipidemic effects [14,15]. Polyphenols from blueberries and/or strawberries reduce the body weight and body fat of rats fed a high-fat diet [16]. Polyphenol rich antioxidants reduced hyperglycemia efficiently in type 2 diabetic mice via inducing AMPK expression in the liver and then resulted in significantly decreased liver and serum lipid contents [17]. Our recent report showed that OPF possesses antioxidant properties [8,9]. Earlier studies revealed that olive oil phenols possess strong antioxidant compounds [18]. In particular, hydroxytyrosol was found in great quantities in the remains from fruit oil processing, such as 
pomace olive oil, olive-mill waste water and rinse waters $[19,20]$. In our present study, the ethyl acetate fraction obtained from the olive fruit pulp extract also exhibited significant free radical scavenging effect, indicating that the fruit pulp extract might contain potential antioxidant agents.

\section{CONCLUSION}

The present study provides evidence that OPF play a significant role in reducing HepG2 cellular lipid accumulation by mediating AMPK signaling, thereby inhibiting expression of SREBP-1c and further suppressing TG and cholesterol synthesis. The antioxidant potential of OPF extract might partly be responsible, suggesting an active role for OPF in preventing nonalcoholic fatty liver disease and also a potential for development into an anti-obesity agent.

\section{REFERENCES}

1. Moller D, Kaufman KD. Metabolic syndrome: a clinical and molecular perspective. Annu. Rev. Med. 2005; 56: $45-62$.

2. Brownsey RW, Boone AN, Elliott EN, Kulpa JE, Lee WM. Regulation of acetyl-C glucose carboxylase. Biochem. Soc. Trans. 2006; 34: 223- 227.

3. Puljak LV, Parameswara S, Dolovcak, SL, Waldrop D, Emmett $V$, Esser JG, Kilic G. Evidence for AMPKdependent regulation of exocytosis of lipoproteins in a model liver cell line Exp. Cell Res. 2008; 314: 2100-2109.

4. Lagouge M, Argmann C, Gerhart-Hines Z. Resveratrol improves mitochondrial function and protects against metabolic disease by activating SIRT1 and PGC1alpha. Cell 2006; 127: 1109-1122.

5. Kiritsakis A. Olive oil- 2 nd edition, From the tree to the table. Food and Nutrition. Press, Inc., Trumbull, Connecticut, USA, 1998.

6. Covas MI. Bioactive effects of olive oil phenolic compounds in humans: reduction of heart disease factors and oxidative damage. Inflam mo pharmacol 2008; 16: 216-218.

7. Rosignoli $P$, Fuccelli $R$, Fabiani $R$, Servili M, Morozzi $G$. Effect of olive oil phenols on the production of inflammatory mediators in freshly isolated human monocytes. J Nutr Biochem 2013; 24(8):1513-1519.

8. Kim MS, Koppula S, Jung SH, Kim JY, Lee HR, Lee SR, Park YD, Lee KA, Park TK, Kang H. Olea europaea Linn (Oleaceae) Fruit Pulp Extract Exhibits Potent Antioxidant Activity and Attenuates Neuroinflammatory Responses in Lipopolysaccharide-
Stimulated Microglial Cells. Trop J Pharm Res 2013; 12: 357-362.

9. Kim MS, Koppula S, Sung SJ, Lee SR, Park YD, Lee KA, Park TK, Kang H. Olea europaea Linn (Oleaceae) Fruit Pulp Exhibits Hypocholesterolemic and Hepatoprotective Effects via Regulation of Peroxisome Proliferation-Activated Receptor Alpha in High-Fat Diet-Fed Rats. Tropical Journal of Pharmaceutical Research January 2014; 13: 31-39.

10. Gil-Campos M, Canete RR, Gil A. Adiponectin, the missing link in insulin resistance and obesity. Clin. Nutr. 2004; 23: 963- 974.

11. Li HB, Ge YK, Zheng XX, Zhang L. Salidroside stimulated glucose uptake in skeletal muscle cells by activating AMP-activated protein kinase Eur. J. Pharmacol. 2008; 588: 165- 169.

12. Banaee M, Sureda A, Mirvaghefi AR, Rafei GR. Effects of long term silymarin oral supplementation on the blood biochemical profile of rainbow trout (Oncorhynchus mykiss). Fish Physiol Biochem. 2011; 37: 885-896.

13. Ou TT, Hsu MJ, Chan KC, Huang CN, Ho HH, Wang CJ. Mulberry extract inhibits oleic acid-induced lipid accumulation via reduction of lipogenesis and promotion of hepatic lipid clearance. J. Sci. Food Agric. 2011; 91: 2740-2748.

14. Hsu CL, Yen GC. Phenolic compounds: Evidence for inhibitory effects against obesity and their underlying molecular signaling mechanisms. Mol. Nutr. Food Res. 2008; 52: 53-61.

15. González R, Ballester I, López-Posadas R, Suárez MD, Zarzuelo A, Martínez-Augustin O, Sánchez de Medina F. Crit. Rev. Food Sci. Nutr. 2011; 51: 331362.

16. Prior RL, Wu X, Gu L, Hager T, Hager A, Wilkes $S$, Howard L. Purified berry anthocyanins but not whole berries normalize lipid parameters in mice fed an obesogenic high fat diet. Mol. Nutr. Food Res. 2009; 53: 1406-1418.

17. Takikawa $M$, Inoue $S$, Horio $F$, Tsuda, $T$. Dietary anthocyanin-rich bilberry extractameliorates hyperglycemia and insulin sensitivity via activation of AMP-activated protein kinase in diabetic mice. J. Nutr. 2010; 140: 527- 533.

18. Raederstorff D. Antioxidant activity of olive polyphenols in humans: a review. Int J Vitam Nutr Res 2009; 79:152-65.

19. Yang DP, Kong DX, Zhang HY. Multiple pharmacological effects of olive oil phenols. Food Chem 2007; 104: 1269-1271.

20. Henn A, Lund S, Hedtjarn M, Schrattenholz A, Porzgen $P$, Leist $M$. The suitability of BV2 cells as alternative model system for primary microglia cultures or for animal experiments examining brain inflammation. Altex 2009; 26: 83-94. 